\title{
Trabalhonecessário
}

Issn: $1808-799 X$

ano 13, número $20-2015$

\section{A PESQUISA EM TRABALHO E EDUCAÇÃO NAS REGIÕES NORTE E NORDESTE}

Ronaldo Marcos de Lima Araujo ${ }^{1}$

Ramon de Oliveira ${ }^{2}$ Georgia dos Santos Cêa ${ }^{3}$

\section{Resumo}

Apresenta um estado da arte da produção da área Trabalho e Educação no Norte e no Nordeste com o qual revela potencialidades, tendências e lacunas. Utiliza-se de análise documental, considerando resumos de teses, dissertações e trabalhos apresentados nas edições do Encontro de Pesquisa Educacional do Norte e Nordeste (EPENN), no período de 2003 a 2012. A partir do uso de três categorias empíricas, temáticas, referências/referenciais e metodologias, identificou que há disparidades em relação à importância atribuída pelos diferentes tipos de produção a determinados temas, mas que é significativa a presença de estudos sobre a educação do campo, de estudos de cunho teórico-metodológico e de análises que tomam as políticas educacionais como objeto, com destaque para o ensino médio integrado e para políticas específicas de formação de trabalhadores. Identificou, ainda, uma séria fragilidade metodológica das produções e uma hegemonia de estudos de perspectivas críticas, fundadas no marxismo. Conclui que a área Trabalho e Educação está consolidada no Norte e

\footnotetext{
1 PPGE/UFPA.

2 PPGE/UFPE.

3 PPGE/UFAL.
}

TrabalhoNecessário - www.uff.br/trabalhonecessario; Ano 13, № 20/2015. 


\section{Trabalhonecessário}

Issn: 1808 - 799X

ano 13, número $20-2015$

no Nordeste, apesar de haver centralização institucional das produções, mas que o seu fortalecimento requer o enfrentamento dos problemas e lacunas levantados. Palavras chave: estado da arte - trabalho e educação - norte e nordeste pesquisa em educação.

\section{Abstract}

This paper presents a state of the art about the production of WORK and EDUCATION area in the North and Northeast of Brazil, which reveals potential, trends and gaps. Were used as source of data document, considering abstracts of theses, dissertations and papers presented in editions of Northern Educational Research Meeting and Northeast (PENN), from 2003 to 2012. Starting from the use of three empirical categories, themes, references/frameworks and methodologies, it was identified that there are differences regarding on the importance attributed by different types of production on some issues. We emphasize that is significant the presence of studies on rural education, theoretical and methodological studies and analysis which takes educational policies as an object, especially the integrated high school and specific policies of training workers. We also identified a serious methodological weakness of production and hegemony studies of critical perspectives, based on Marxism. It follows that the work and education area are consolidated in the North and Northeast of Brazil, although there institutional centralization of production, but the strengthening requires face the problems and gaps indicated.

Keywords: state of the art - work and education - north and northeast - research in education. 


\section{Trabalhonecessário}

Issn: 1808 - 799X

ano 13, número $20-2015$

\section{Introdução}

Este texto tem como objetivo apresentar os resultados de uma pesquisa voltada à construção do estado da arte da produção da área Trabalho e Educação no Norte e no Nordeste ${ }^{4}$. Com este estudo buscou-se revelar potencialidades a serem afirmadas, tendências indicadas e lacunas que mereçam consideração. Em outras palavras, representa um levantamento e avaliação do conhecimento produzido pela área, considerando teses, dissertações e trabalhos apresentados nas edições do Encontro de Pesquisa Educacional do Norte e Nordeste (EPENN), no período de 2003 a 2012, com vistas a contribuir com a solidificação da trajetória de pesquisadores e de programas de pós-graduação em educação (PPGE).

Diante da impossibilidade de abarcar a totalidade do que se produz na área de trabalho e educação, o recorte teórico-metodológico do estudo considerou como fontes privilegiadas resumos de teses e dissertações defendidas de 2003 a $2012^{5}$ em programas de pós-graduação em educação do Norte e do Nordeste e resumos de trabalhos apresentados nas edições do EPENN de 2003, 2005, 2007, 2009 e 20116. Trata-se, portanto, de uma pesquisa "[...] de levantamento e de avaliação do conhecimento sobre determinado tema" (FERREIRA, 2002, p. 259), de modo a permitir uma

[...] visão geral do que vem sendo produzido na área e uma ordenação que permit[a] aos interessados perceberem a evolução

\footnotetext{
${ }^{4} \mathrm{~A}$ pesquisa atendeu a uma demanda da coordenação do XXI Encontro de Pesquisa Educacional do Norte e Nordeste (EPENN), realizado na Universidade Federal de Pernambuco, no período de 10 a 13 de novembro de 2013. Na ocasião, a coordenação definiu o mesmo tema para os trabalhos encomendados dos grupos de trabalho: o estado da arte da produção nas diferentes áreas.

5 Disponíveis no Banco de Teses e Dissertações da CAPES, com recorte para as regiões Norte e Nordeste, no período de 2003 a 2012.

${ }^{6}$ Disponíveis nos anais das edições do EPENN de 2003, 2005, 2007, 2009 e 2011.

TrabalhoNecessário - www.uff.br/trabalhonecessario; Ano 13, № 20/2015.
} 
Issn: $1808-799 X$

ano 13, número $20-2015$

das pesquisas na área, bem como suas características e foco, além de identificar as lacunas ainda existentes.

$\mathrm{Na}$ intenção de abarcar o maior número possível de produções, optou-se no estudo pelo tratamento de resumos, visto que eles têm a potencialidade de apresentar elementos essenciais do texto/material resumido. Portanto, o estudo em tela elegeu três categorias básicas para a exploração dos resumos: temáticas, referências/referenciais e metodologias. Essas categorias foram consideradas menos ambíguas - mas não menos densas - e mais producentes para o objetivo proposto, visto que constituem elementos básicos de resumos ${ }^{7}$.

As teses, dissertações e trabalhos trataram de uma grande variedade de temáticas. Para efeitos da análise empreendida, tais temáticas foram assim classificadas: a) Questões conceituais e de fundamentação teórica; b) Políticas educacionais, de ensino médio e de educação profissional; c) Formação do trabalhador; d) Questões escolares e pedagógicas; e) Educação e movimentos sociais e educação do campo.

Foram considerados83 resumos de teses, 81 resumos de dissertações e 143 resumos apresentados no GT 9 das edições do EPENN, perfazendo uma amostra final $^{8}$ de 307 resumos, os quais representam cerca de $17 \%$ do universo

\footnotetext{
7 Segundo a NBR 6023/2003, da ABNT, um resumo se constitui em uma "Apresentação concisa dos pontos relevantes de um documento", podendo ser assim classificado:

"2.3 resumo crítico: Resumo redigido por especialistas com análise crítica de um documento. Também chamado de resenha. Quando analisa apenas uma determinada edição entre várias, denomina-se recensão.

2.5 resumo indicativo: Indica apenas os pontos principais do documento, não apresentando dados qualitativos, quantitativos etc. De modo geral, não dispensa a consulta ao original.

2.6 resumo informativo: Informa ao leitor finalidades, metodologia, resultados e conclusões do documento, de tal forma que este possa, inclusive, dispensar a consulta ao original" (ASSOCIAÇÃO BRASILEIRA DE NORMAS TÉCNICAS, 2003, p. 1). Os resumos analisados pertencem, em sua maioria, aos de terceiro tipo (informativo), mesmo considerando que a maioria deles carece de melhor elaboração.

8 Trata-se de uma amostra não probabilística por tipicidade. Não probabilística porque não se orienta por uma "fundamentação matemática ou estatística, dependendo de critérios do TrabalhoNecessário - www.uff.br/trabalhonecessario; Ano 13, №20/2015.
} 
Issn: 1808 - 799X

ano 13 , número $20-2015$

identificado ${ }^{9}$.Em sua maioria, trata-se de produções de discentes e docentes dos 32 cursos de pós-graduação existentes nas regiões Norte e Nordeste até o ano de 2013.

O texto tem início com a apresentação sintética das principais evidências da análise empreendida considerando cada tipo de resumo tratado - teses, dissertações e trabalhos - e, na sequência, serão trazidos alguns destaques considerados relevantes.

\section{Evidências dos resumos de teses ${ }^{10}$ defendidas em PPGE do Norte e do Nordeste:}

Para efeitos deste estudo, foram considerados 83 (oitenta e três) resumos de teses da área de Trabalho e Educação defendidas nos programas de pósgraduação em educação das regiões Norte e Nordeste do Brasil, no período de 2003 a 2012.

No que concerne às temáticas, as questões de cunho mais conceitual são muito enfatizadas na produção da área. Elas buscam avaliar a fundamentação teórica e/ou aprofundar conceitos teóricos. Merecem destaque os estudos que se

pesquisador" (GIL, 1987, p. 93) e definida por tipicidade porque se considera a capacidade dos pesquisadores em reconhecê-la como representativa em relação à população (GIL, 1987).

${ }^{9} \mathrm{Em}$ percentuais relativos ao universo das produções, isso significa que foram considerados cerca de $10 \%$ das teses identificadas, $11 \%$ das dissertações e $57 \%$ dos trabalhos apresentados no GT 9 do EPENN. As justificativas e explicações sobre a especificidade da seleção empreendida em cada tipo de material serão apresentadas ao longo deste texto.

10 Esta seção foi construída em colaboração com bolsistas do Projeto Práticas Formativas da Juventude Trabalhadora no Ensino Médio Integrado, financiado pelo Obeduc-Capes, a saber: Ana Maria Raiol da Costa, Lorena Teixeira, Michelle Ferreira, Pâmella Almeida, Bárbara Campos, Leide Lima e Brenda Leitão. Foram elas que fizeram os levantamentos das teses, a leitura inicial e a construção dos fichamentos e também acompanharam de perto a produção textual, fazendo as correções e adequações que se mostraram necessárias.

TrabalhoNecessário - www.uff.br/trabalhonecessario; Ano 13, № 20/2015. 


\section{Trabalhonecessário}

Issn: $1808-799 X$

ano 13 , número $20-2015$

propõem a aprofundar e/ou interpretar o marxismo em sua leitura da relação trabalho e educação.

Estudos sobre políticas educacionais também são muito correntes. Entre estes se destacam as avaliações de programas e, em particular, o Programa Nacional de Integração da Educação Profissional com a Educação Básica na Modalidade de Jovens e Adultos (PROEJA). O ensino médio, a educação profissional e questões relativas à juventude também apareceram em várias pesquisas com foco em políticas.

Questões relacionadas à formação do trabalhador também aparecem com frequência, com destaque para os temas da qualificação e da formação do trabalhador frente às mudanças no mundo do trabalho.

Outro grupo de temas aqui considerados, apesar de não predominantes, é relativo a questões de caráter mais pedagógico ou escolar. Predominam, nesse grupo, temas relativos ao ensino médio integrado, particularmente a sua dimensão curricular.

Por fim, os estudos que enfocam temas que articulam educação e movimentos sociais e educação do campo conformam um grupo importante. No caso da educação do campo, em particular, prevalecem estudos sobre as experiências educacionais do MST.

A formação e/ou a prática dos professores não foi uma categoria utilizada, mas o tema apareceu transversalmente em vários resumos.

Embora os 83 resumos tenham sido considerados para a identificação deste aspecto, as metodologias utilizadas nas teses parecem estar mal explicitadas nos mesmos - o que pode indicar também um mau uso ou uma limitada compreensão das metodologias.

Quanto às referências teórico-metodológicas, prevalece o materialismohistórico. No conjunto, predominam pesquisas de tipo qualitativo, sem maiores 


\section{Trabalhonecessário}

Issn: $1808-799 X$

ano 13, número $20-2015$

explicações sobre o que significam. Entre estas, ganham destaque as pesquisas documentais, bibliográficas e de campo - também mal definidas.

Entre os procedimentos, há um predomínio do uso de enquetes de diferentes tipos, com destaque para a entrevista (44 citações) e questionários (15 citações).

Entre as teses que indicaram as suas referências, observou-se que prevalecem abordagens que se referenciam no marxismo. Mais de um terço (32\%) dos resumos de teses que indicam referências citam: Marx, Gramsci, Lukács ou marxismo, materialismo histórico e dialético como referências para o estudo empreendido (16 indicações de um total de 50). Outras referências que apareceram mais de uma vez foram John Dewey, Paulo Freire, Pierre Bourdieu e a fenomenologia.

\section{Evidências dos resumos de dissertações defendidas em PPGE do Norte e do Nordeste:}

Dos 737 resumos de dissertações identificados, entendemos que apenas 81 enquadram-se nas pesquisadas vinculadas aos temas do GT Trabalho e Educação. Assim, este foi o total que compõe a amostra final para a consideração das dissertações relacionadas ao campo teórico e de pesquisa do GT Trabalho e Educação.

É importante destacar que embora não sejam pesquisas vinculadas ao nosso GT, mais de 650 dissertações de alguma forma envolveram-se com temáticas que são centrais para nossas investigações.

Antes de apresentar as evidências encontradas nos resumos analisados, vale a pena destacar a concentração da produção em três programas: UFC 


\section{Trabalhonecessário}

Issn: 1808 - 799X

ano 13 , número $20-2015$

(Universidade Federal do Ceará), UFPA (Universidade Federal do Pará) e UFPE (Universidade Federal de Pernambuco). Esta concentração talvez possa ser justificada pela existência de grupos de pesquisa já consolidados há mais de uma década nessas instituições.

Dos 81 resumos analisados, 55 (68\%) são de dissertações defendidas nestes três programas e quase $50 \%$ dos trabalhos foram orientados por apenas três professores, membros destes programas.

Entre os temas abordados nas dissertações destacam-se com maior expressão: Educação profissional no sistema S;papel das centrais sindicais na qualificação profissional, mais particularmente sua relação com o poder público no âmbito dos programas nacionais de qualificação profissional, em especial o Programa Nacional de Inclusão de Jovens (PROJOVEM) e o PROEJA; experiências de implementação do ensino médio integrado; reforma da educação profissional ocorrida nos anos 1990; experiências de educação profissional realizados no interior das empresas.

O quadro abaixo apresenta, além dessas temáticas, outras também contempladas nas dissertações defendidas entre os anos de 2003 e 2012: 


\section{Trabalhonecessário}

Issn: 1808 - 799X

ano 13 , número $20-2015$

Quadro 1 - Principais temas enfocados em resumos de dissertações na área de Trabalho e Educação no Norte e Nordeste - Por categorias - 2003 a 2012

\begin{tabular}{|c|c|c|c|c|}
\hline $\begin{array}{l}\text { Questões } \\
\text { conceituais e de } \\
\text { fundamentação } \\
\text { teórica }\end{array}$ & $\begin{array}{l}\text { Políticas } \\
\text { educacionais, } \\
\text { de ensino } \\
\text { médio e de } \\
\text { educação } \\
\text { profissional }\end{array}$ & $\begin{array}{l}\text { Formação do } \\
\text { trabalhador }\end{array}$ & $\begin{array}{l}\text { Questões } \\
\text { escolares e } \\
\text { pedagógicas }\end{array}$ & $\begin{array}{l}\text { Educação e } \\
\text { Movimentos } \\
\text { sociais e } \\
\text { educação do } \\
\text { campo }\end{array}$ \\
\hline $\begin{array}{l}\text { Reorganização } \\
\text { da produção e } \\
\text { qualificação dos } \\
\text { trabalhadores }\end{array}$ & $\begin{array}{l}\text { Programas } \\
\text { oficiais diversos } \\
\text { (PROJOVEM, } \\
\text { PROEJA, } \\
\text { Programa Mais } \\
\text { Educação, } \\
\text { Programa Bolsa } \\
\text { Trabalho) }\end{array}$ & $\begin{array}{l}\text { Educação } \\
\text { profissional no } \\
\text { sistema S }\end{array}$ & $\begin{array}{l}\text { Saberes dos } \\
\text { trabalhadores }\end{array}$ & $\begin{array}{l}\text { Papel das } \\
\text { centrais } \\
\text { sindicais na } \\
\text { qualificação } \\
\text { profissional }\end{array}$ \\
\hline \multirow[t]{7}{*}{$\begin{array}{l}\text { Precarização do } \\
\text { trabalho }\end{array}$} & $\begin{array}{l}\text { Experiências de } \\
\text { implementação } \\
\text { do ensino médio } \\
\text { integrado }\end{array}$ & $\begin{array}{l}\text { Experiências de } \\
\text { educação } \\
\text { profissional em } \\
\text { empresas }\end{array}$ & & $\begin{array}{l}\text { Educação } \\
\text { profissional } \\
\text { no MST }\end{array}$ \\
\hline & $\begin{array}{l}\text { Reforma da } \\
\text { educação } \\
\text { profissional dos } \\
\text { anos } 1990\end{array}$ & $\begin{array}{l}\text { Qualificação } \\
\text { profissional na } \\
\text { área rural }\end{array}$ & & \\
\hline & $\begin{array}{l}\text { Projeto Somem } \\
\text { - PA (Sistema } \\
\text { Organizacional } \\
\text { Modular do } \\
\text { Ensino Médio) }\end{array}$ & $\begin{array}{l}\text { Inserção de } \\
\text { crianças no } \\
\text { mercado de } \\
\text { trabalho }\end{array}$ & & \\
\hline & $\begin{array}{l}\text { Educação } \\
\text { profissional no } \\
\text { governo Lula }\end{array}$ & $\begin{array}{l}\text { Relação escola- } \\
\text { empresa }\end{array}$ & & \\
\hline & $\begin{array}{l}\text { Juventude e } \\
\text { mercado de } \\
\text { trabalho }\end{array}$ & $\begin{array}{l}\text { Formação por } \\
\text { competências e } \\
\text { empregabilidade }\end{array}$ & & \\
\hline & $\begin{array}{l}\text { Educação } \\
\text { profissional nos } \\
\text { institutos } \\
\text { federais }\end{array}$ & & & \\
\hline & $\begin{array}{l}\text { História da } \\
\text { educação } \\
\text { profissional }\end{array}$ & & & \\
\hline
\end{tabular}

As temáticas PROJOVEM, ensino integrado e PROEJA, embora só apareçam basicamente a partir dos anos 2007 e 2008, a partir do ano de 2009

TrabalhoNecessário - www.uff.br/trabalhonecessario; Ano 13, № 20/2015. 


\section{Trabalhonecessário}

Issn: $1808-799 X$

ano 13, número $20-2015$

passaram a ser as que mais interesse receberam nas dissertações. Entre 2009 e 2012, 32 resumos foram analisados e, destes, 29 se relacionam a uma dessas três temáticas, o que representa um percentual de mais de $60 \%$.

Neste sentido, é expressivo o quantitativo de trabalhos que analisam empiricamente as experiências de qualificação profissional desenvolvidas por algumas das centrais sindicais, por alguma instituição ligada à rede federal de educação tecnológica, por empresas privadas ou públicas, por movimentos sociais rurais, etc.

Semelhante às teses, as dissertações, em sua grande maioria, utilizaram o referencial marxista como norteamento teórico, embora se registre a presença de bom número de dissertações que apontam em seus objetivos o interesse em trabalhar com representações sociais.

\section{Evidências dos resumos dos trabalhos apresentados no EPENN:}

Seis instituições tiveram participação mais orgânica na apresentação de trabalhos: UFC, UFMA (Universidade Federal do Maranhão), UFPA, UFPE, UFAL (Universidade Federal de Alagoas) e UFRN (Universidade Federal do Rio Grande do Norte).

Observa-se a diminuição de trabalhos da UFC e da UFMA, a tendência de crescimento de trabalhos da UFPA e certa constância de trabalhos da UFPE, UFAL e UFRN.

Talvez o fato da diminuição do peso de trabalhos em eventos nas avaliações trienais da Capes tenha implicado em mudança de estratégia dos PPGE da UFC e da UFMA no que tange aos espaços de divulgação de suas pesquisas.

TrabalhoNecessário - www.uff.br/trabalhonecessario; Ano 13, № 20/2015. 


\section{Trabalhonecessário}

Issn: $1808-799 X$

ano 13, número $20-2015$

Quanto aos tema dos trabalhos apresentados, observamos que embora a categoria "Formação do trabalhador" apresente a mesma quantidade de grupos de temas da categoria "Políticas educacionais, de ensino médio e de educação profissional", esta dividiu a predominância de temas dos trabalhos com a categoria "Questões conceituais e de fundamentação teórico-metodológica". Juntas, essas categorias congregam 127 dos 250 trabalhos apresentados no GT 9 do EPENN; ou seja, praticamente a metade deles.Se a elas se juntar a categoria "Formação do trabalhador", se chega ao fato de 3 categorias abarcarem cerca de $72 \%$ dos temas dos trabalhos apresentados no GT 9 do EPENN (181 trabalhos, do total de 250).

É considerável o fato de temas como saúde do trabalhador e processos de trabalho ${ }^{11}$ ganharem espaço entre os trabalhos do GT 9, embora esses mesmos temas não terem ganhado expressão nas análises dos resumos das teses e das dissertações. Isso pode indicar duas possibilidades: recortes específicos dessas produções para apresentação no evento ou potencialidade do GT 9 para abarcar temas trabalhados em outras áreas, de forma transversal.

No referente à análise das metodologias privilegiadas nos trabalhos apresentados no GT 9 do EPENN não foram consideradas as edições de $2003 \mathrm{e}$ de 2009, visto que não se teve acesso aos resumos. Da mesma forma, não foi possível considerar os 143 resumos analisados, visto que 26 deles não apresentaram informações sobre metodologia dos estudos realizados. Dessa forma, para o levantamento deste aspecto, foram considerados 117 resumos.

As informações sobre metodologias foram organizadas em categorias, conforme exposto a seguir:

\footnotetext{
11 Todos os trabalhos sobre saúde do trabalhador se referiram ao trabalho docente. Entre as produções que analisaram processos de trabalho, em diferentes interfaces com a educação, foram identificados as seguintes categorias de trabalhadores: professores do ensino superior; catadores de material reciclável; apenados; bancários; mulheres empreendedoras; guias de turismo; trabalhadores da cana-de-açúcar.
}

TrabalhoNecessário - www.uff.br/trabalhonecessario; Ano 13, № 20/2015. 


\section{Trabalhonecessário}

Issn: 1808 - 799X

ano 13, número $20-2015$

Quadro 2 - Metodologias enfocadas nos trabalhos apresentados no GT 9 do EPENN - 2003 a 2011

\begin{tabular}{|l|l|c|}
\hline \multicolumn{1}{|c|}{ Aspecto metodológico } & \multicolumn{1}{|c|}{ Detalhamento } & $\begin{array}{c}\text { Quantidade de } \\
\text { aparições }\end{array}$ \\
\hline \multirow{5}{*}{ Tipo de pesquisa } & Pesquisa bibliográfica & 20 \\
\cline { 2 - 3 } & Pesquisa documental & 6 \\
\cline { 2 - 3 } & Pesquisa de campo & 6 \\
\cline { 2 - 3 } & Estado da arte & 4 \\
\cline { 2 - 3 } & Estudo de caso & 9 \\
\cline { 2 - 3 } & Estudo etnográfico & 1 \\
\cline { 2 - 3 } & Pesquisa autobiográfica & 10 \\
\hline Abordagem & Qualitativa & 2 \\
\cline { 2 - 3 } & Qualiquantitativa & 11 \\
\hline Referência metodológica & Materialismo histórico-dialético & 3 \\
\cline { 2 - 3 } & Ontologia marxiana-lukcsiana & 5 \\
\cline { 2 - 3 } & Outros & 26 \\
\hline \multirow{5}{*}{ Instrumentos e procedimentos } & Entrevistas & 11 \\
\cline { 2 - 3 } & Questionários & 6 \\
\cline { 2 - 3 } & Observação & 1 \\
\cline { 2 - 3 } & Diário de campo & 3 \\
\cline { 2 - 3 } & História de vida / História oral / Narrativas & 20 \\
\cline { 2 - 3 } & Instrumentos e técnicas & 47 \\
\hline \multirow{5}{*}{ Tipo de análise } & Análise documental & 6 \\
\cline { 2 - 3 } & Análise teórica & 5 \\
\cline { 2 - 3 } & Revisão bibliográfica & 4 \\
\cline { 2 - 3 } & Análise do discurso / Análise de conteúdo & \\
\hline
\end{tabular}

Considerando os resumos dos trabalhos apresentados no GT 9 do EPENN - nas edições de 2005, 2007 e 2011 -, se identifica que a maioria dos estudos se caracteriza como pesquisa bibliográfica, embora a análise documental seja o tipo de análise mais incidente e as entrevistas e questionários os principais instrumentos e procedimentos indicados.

Os trabalhos apresentados no GT 9 das edições do EPENN consideradas confirmam a vocação crítica da área. Mostra-se evidente o predomínio do

12 Multirreferencialidade; História cultural; Pedagogia libertadora; Teoria das representações sociais; Dialogia bakhtiniana.

13 Instrumento Job Content Questionnaire (JCQ); Modelo de O'Reilly e Chatman; Modelo de Meyer, Allen e Smith.

TrabalhoNecessário - www.uff.br/trabalhonecessario; Ano 13, № 20/2015. 


\section{Trabalhonecessário}

Issn: $1808-799 X$

ano 13, número $20-2015$

referencial marxiano/marxista, visto que as citações de Karl Marx/Materialismo histórico representam cerca de $38 \%$ dos autores/referenciais citados.

Considerando-se os demais autores que aprofundam aspectos da obra marxiana, essa margem é ainda mais expressiva: György Luckás/Ontologia marxiano-lukacsiana, Istvan Mészáros e Antonio Gramsci são autores/referenciais que compõem perto de $73 \%$ do total dos autores/referenciais mais citados nos trabalhos apresentados no GT 9 do EPENN que prestaram essas informações.

\section{Outras reflexões acerca do material analisado}

No que concerne ao estado da arte da pesquisa em Trabalho e Educação nas regiões Norte e Nordeste - delineado nas evidências e análises das teses, dissertações e trabalhos apresentados no GT 9 do EPENN- sinteticamente aqui trazidas -, alguns destaques parecem urgentes. Sem intenção de meramente reproduzir dados e elementos apresentados ao longo do texto, esses destaques considerarão cada um dos elementos privilegiados na exploração e análise dos tipos de resumos analisados:

a) Sobre os temas: O estudo explicita a diversidade, riqueza, pertinência e atualidade dos temas tratados em pesquisas da área, abordando questões que vão desde o debate, aprofundamento e fundamentação do campo teórico, até espaços e práticas de sujeitos sociais específicos, passando por políticas e ações voltadas para a formação de trabalhadores.Entretanto, se verificou disparidades em relação à importância atribuída pelos diferentes tipos de produção considerados (teses, dissertações, trabalhos) a determinados temas, organizados em categorias (Questões conceituais e de fundamentação teóricometodológica; Políticas educacionais, de ensino médio e de educação 


\section{Trabalhonecessário}

Issn: $1808-799 X$

ano 13, número $20-2015$

profissional; Formação do trabalhador; Questões escolares e pedagógicas; Educação e Movimentos sociais e educação do campo).

Dois exemplos ilustram esta situação: O primeiro refere-se ao fato de as questões escolares e pedagógicas terem menos presença do que as demais categorias, o que permite indagar o nível de importância que a área tem atribuído à escola e às práticas concernentes a esse espaço social complexo e conflituoso.

Decerto que muitos temas de política educacional, a depender dos objetos considerados, passam por práticas que se desenvolvem nesse espaço, mas isso ocorre de forma contingente e tangencial; as dissertações tendem a considerar este quesito, mais do que o fazem as teses e os trabalhos.

O segundo exemplo diz respeito a temas que aparecem com mais intensidade nos trabalhos do que nas teses e dissertações, como saúde do trabalhador e processos de trabalho envolvendo categorias diversas de trabalhadores. Entretanto, a configuração do mundo do trabalho aparece como objeto de muitos estudos de cunho teórico e bibliográfico. Isso permite indagar em que medida tais estudos vêm considerando ou não a realidade objetiva e os trabalhadores "de carne e osso".

Em relação a este segundo exemplo a exceção é a significativa presença de estudos sobre a educação do campo - com destaque quase que exclusivo para a orientação político-ideológica do MST - e de estudos sobre a dimensão educativa na ótica da CUT, ambos com mais presença nas teses e dissertações do que nos trabalhos apresentados no GT 9 do EPENN.

Por fim, quanto aos temas, nos resumos das teses, dissertações e trabalhos é notória a predominância de estudos de cunho teórico-metodológico e, mais ainda, de análises que tomam as políticas educacionais como objeto, com destaque para o ensino médio integrado e para políticas específicas de formação de trabalhadores. Esse fato, embora demonstre a preocupação da área com a 


\section{Trabalhonecessário}

Issn: $1808-799 X$

ano 13, número $20-2015$

direção dada à formação de trabalhadores pelas políticas oficiais, pode representar um risco, caso representem "[...] uma tendência de colagem às agendas de política educativa,[...] dificultando o exercício de uma distância crítica [...]" (LIMA, 2003, p. 2, grifos do autor).

b) Sobre as metodologias: Aqui se encontra o ponto mais problemático da produção analisada e mais destacado ao longo da análise dos resumos das teses, dissertações e trabalhos: a séria fragilidade das fontes analisadas pode indicar dificuldade e/ou secundarização da área de Trabalho e Educação, nas regiões consideradas,frente ao trato e explicitação de elementos metodológicos (referencial, método, abordagem, tipo de pesquisa, clareza do objeto e da problemática, objetivos, fontes, procedimentos, instrumentos, técnicas, evidências, conclusões, para citar os principais). Nesse ponto, a elevada e dedicada preocupação com as dimensões teóricas, evidenciada nos resumos analisados, é incongruente com a ausência de cuidado e zelo com as questões de método, metodologia e procedimentos de investigação.

Incompreensões de diferentes naturezas foram identificadas nas análises empreendidas neste estudo. Mas parece importante assinalar que se o método de análise não se confunde com o método de exposição - advertência teóricometodológica marxiana tão cara à área -, o rigor deve caracterizar ambos. Menos que uma desqualificação das produções, o reconhecimento dessa fragilidade pode incitar o aprimoramento dos estudos realizados e abrir espaço para o enfrentamento coletivo das condições precárias e competitivas que marcam o espaço acadêmico e que vêm promovendo o aligeiramento e a superficialidade da prática da pesquisa.

c) Sobre os referenciais: Significativamente, os referenciais constituem o aspecto menos privilegiado nos resumos analisados, nos três tipos de produção considerados. Isso pode estar relacionado com as fragilidades metodológicas 


\section{Trabalhonecessário}

Issn: $1808-799 X$

ano 13, número $20-2015$

antes apresentadas, mas também pode indicar que vigora a compreensão equivocada de que os temas anunciados revelam, por si só, as referências/referenciais teóricos basilares de uma dada investigação, como se aos temas tratados estivessem naturalmente aderidos os referenciais de análise.

Mesmo sendo pequena a quantidade de resumos de cada tipo de produção que permitiu apreender tendências quanto aos referenciais, nos arriscamos a afirmar a hegemonia de perspectivas críticas, fundadas no marxismo, na área de Trabalho e Educação no Norte e no Nordeste.

No caso das dissertações e dos trabalhos, o marxismo é o referencial majoritariamente indicado e nas teses este aparece de forma significativa, embora divida espaço com outros referenciais, como o estruturalismo, a fenomenologia e mesmo o neomarxismo, como se pode inferir a partir dos teóricos nominalmente citados em alguns resumos. Entende-se que esse aspecto específico das teses não significa, necessariamente, perda de primazia do referencial marxista, mas que a elaboração de teses exige aprofundamentos e diálogos teóricos mais amplos e diversos. Por fim, se destaca o fato de "documentos" serem indicados em diversos resumos - de teses, dissertações e trabalhos - como "referenciais". Seria isso sinal da tendência de colagem dos temas de pesquisas às agendas políticas educativas pautadas pelo Estado, conforme indica Lima (2003), ou mera repercussão da fragilidade metodológica no que se compreende como referencial teórico?

Além de aspectos qualitativos acima indicados, alguns dados quantitativos merecem ser destacados para contribuir com a reflexão sobre a produção da área tratada no estudo, o que será feito a seguir.

A quantidade de teses, dissertações e trabalhos indica que a área Trabalho e Educação está consolidada no Norte e no Nordeste. 


\section{Trabalhonecessário}

Issn: $1808-799 X$

ano 13, número $20-2015$

Na década considerada, 2003 a 2012, foram identificadas: a) 83 teses e 81 dissertações marcadamente afetas à área Trabalho e Educação, o que perfaz uma média de 16 produções desse tipo por ano; b) 250 trabalhos apresentados no GT 9 do EPENN, ou seja, cerca de 25 trabalhos por edição. Entretanto, a dispersão dessa produção é marcada por forte centralização institucional: no caso das dissertações consideradas, 65\% foram originadas de 3 PPGE: UFC, UFBA (Universidade Federal da Bahia) e UFPE; no caso do GT 9 do EPENN, 6 instituições (as 3 citadas, mais UFMA, UFAL e UFRN) concentraram, na década considerada, $47 \%$ dos trabalhos apresentados. Nesse sentido, parece desejável elaborar estratégias coletivas de articulação orgânica desses mesmos grupos/linhas/pesquisadores, de modo a articular e desenvolver estudos que tomem como objeto questões nevrálgicas e problemáticas afetas à área, considerando, especialmente, as realidades regionais.

Outro ponto que nos chamou atenção é o fato de apenas 10 grupos de pesquisa da área Trabalho e Educação destas regiões indicarem participação ativa no GT 9 da Anped. Nesse sentido, seria pertinente que o GT 9 do EPENN buscasse considerar mais em sua programação a discussão dessa e de outras questões que atingem a área nestas regiões, de modo que os encontros do referido GT nas edições desse importante evento estimulem e propiciem a organização política-acadêmica dos participantes.

\section{Considerações finais}

O intento do estado da arte apresentado neste texto foi colocar em debate uma determinada leitura do panorama da pesquisa na área de Trabalho e Educação, no Norte e Nordeste, considerando o período de 2003 a 2012. 


\section{Trabalhonecessário}

Issn: $1808-799 X$

ano 13, número $20-2015$

Reconhecemos e destacamos, de imediato, dois importantes limites postos a este estudo, de naturezas distintas: o primeiro é referente às condições para a sua realização, especialmente quanto ao tempo disponível para o levantamento e tratamento dos dados e para a maturação das análises;o segundo diz respeito à fragilidade das principais fontes consultadas: os resumos de teses e dissertações afetas à área Trabalho e Educação e os resumos de trabalhos apresentados no GT 9 do EPENN.

Quanto ao primeiro limite, se buscou contorná-lo a partir da definição coletiva de um cronograma de trabalho e de metodologias e processos de levantamento e análise de dados compatíveis com as condições postas, o que exigiu dos autores estratégias várias de articulação. Se não foi possível corresponder à tarefa nesse aspecto, assumem os autores a responsabilidade pelas lacunas deste estudo, especialmente quanto as suas análises.

Quanto ao segundo limite indicado, se tinha ideia, de antemão, que o tipo de fonte definido - resumos - impunha limites a um estudo objetivando o estado da arte de determinado campo, conforme salientam nossas referências. Entretanto, a frágil qualidade da maioria dos resumos constituiu um limite instransponível e que exigiu dos autores atenção e zelo significativos, na busca de extrair dos resumos o máximo de elementos passíveis de análise.

Portanto, este texto assume seus limites e riscos, sem abdicar de sua finalidade última, que é estimular o debate sobre tendências e rumos da área Trabalho e Educação junto aos pares que a compõem e que atuam em instituições, grupos de pesquisa e programas de pós-graduação em educação do Norte e do Nordeste.

Os parágrafos finais do texto retornam ao seu início, retomando, em novas bases, a problemática anunciada: o que o estado da arte da produção da área Trabalho e Educação no Norte e no Nordeste pode revelar em termos de 


\title{
Trabalhonecessário
}

Issn: 1808 - 799X

ano 13, número $20-2015$

potencialidades a serem afirmadas, tendências indicadas e lacunas que mereçam consideração?Todo o caminho percorrido no estudo empreendido, na busca de enfrentar essa questão, mostrou o quão complexo ela é o tanto de percurso que ainda há por trilhar. Exercitou-se, até aqui, um estado da arte e um exercício de crítica inconclusos, pois

\begin{abstract}
Não se trata, como pode parecer a uma visão vulgar de "crítica", de se posicionar frente ao conhecimento existente para recusá-lo ou, na melhor das hipóteses, distinguir nele o "bom" do "mal". Em Marx, a crítica do conhecimento acumulado consiste em trazer ao exame racional, tornando-os conscientes, os seus fundamentos, os seus condicionamentos e os seus limites - ao mesmo tempo em que se faz a verificação dos conteúdos desse conhecimento a partir dos processos históricos reais (NETTO, 2011, p. 18).
\end{abstract}

Espera-se que este texto possa estimular os pesquisadores da área de estudos e pesquisas sobre Trabalho e Educação do Norte e do Nordeste, principalmente, a darem continuidade ao exercício de exame racional do conhecimento acumulado, exame esse aqui apenas iniciado e que serviu aos autores do texto - pesquisadores da área - como um exercício de autocrítica. Quanto à consideração dos processos históricos reais, essa é uma tarefa que, por ora, esses mesmos autores a anunciam como um convite aos seus pares.

\section{Referências}

ASSOCIAÇÃO BRASILEIRA DE NORMAS TÉCNICAS. NBR 6028: Informação e documentação - Resumo - Apresentação. Rio de Janeiro, nov. 2003.

FERREIRA, Norma Sandra de Almeida. As pesquisas denominadas "estado da arte". Educação \& Sociedade, v. 23, n. 79, ago. 2002. p. 257-272.

GIL, Antonio Carlos. Métodos e técnicas de pesquisa social. São Paulo: Atlas, 1987. 
Issn: 1808 - 799X

ano 13 , número $20-2015$

LIMA, Licínio. Editorial. In: Licínio LIMA, Licínio (ed.). Investigar em Educação, Revista da Sociedade Portuguesa de Ciências da Educação, n. 2, Lisboa: SPCE, 2003. p. 8-11.

NETTO, José Paulo. Introdução ao estudo do método de Marx. São Paulo: Expressão Popular, 2011.

Recebido em 12 de dezembro de 2014 Aprovado em 28 de janeiro de 2015 